\title{
Determining effective criteria on sustainable development of fluting paper making industry
}

\section{Majid Azizi (iD, Nemat Mohebbi, Mohammad Azadfallah}

College of Agriculture and Natural Resources, University of Tehran,

Faculty of Natural Resources, Wood and Paper Sciences and Technology Department

16th Azar St., Enghelab Sq., Tehran, Iran

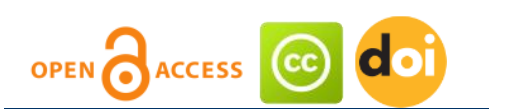

Article history:

Received: May 28, 2018

1st Revision: July 5, 2018

Accepted: September 11, 2018

\section{JEL classification:}

D4

L11

Q13

\section{DOI:}

10.14254/jems.2018.3-2.2

\begin{abstract}
Fluting paper industry seems to be significant from environmental view point. Accordingly, study on sustainable development criteria in this sector of Iran's industry is regarded as a national necessity. The intent of the current study is to determine and prioritize the indices affecting sustainable development of Iran's fluting paper industry by benefiting from Analytical Hierarchy Process (AHP) method. After the conducted investigations, 55 indices were identified and categories in eight general groups namely, technical \& human, cultural-social, economic, materials \& products, rules and regulations, environmental, infrastructure and sale \& marketing . Analytical Hierarchy Process was applied in the form of adjusting and distributing questionnaires among professional experts. Results show that the highest priorities for attaining sustainable development in this industry respectively belong to sub-criteria of economic stability increase in the country, a continuous relation between university and industry, privatization, training man force, paper recycling, foreign investment, increasing productivity and reducing greenhouse gas emissions.
\end{abstract}

Keywords: criteria and sub criteria, weighing value, group decision making, Analytical Hierarchy Process, sustainable development, fluting paper.

\section{Introduction}

All industry players operating in today's cash constrained environment need to reduce the cost of their operations to improve returns. Water and energy consumption are critical cost drivers: worldwide, the pulp and paper industry is among the largest consumers of both, compared to other sectors (Fig. 1, 2). A recent study carried out by McKinsey \& Company identified more than 20 opportunities available to pulp and paper companies to reduce their consumption of energy and

Corresponding author: Majid Azizi

E-mail:mazizi@ut.ac.ir

This open access article is distributed under a Creative Commons Attribution (CC-BY) 4.0 license. 
water, ranging from retrofitting buildings to improve the overall efficiency of the machinery to improving water treatment systems. Implementing those measures will most likely lead to increasing returns on capital. Opportunities to save water and energy arise at every step in production processes, starting in the forest, where applying best practice forest management techniques will produce fiber with properties that allow it to be pulped using less energy, and running through to papermaking, where introducing steam recovery and finishing will save both energy and water. Indeed, following sustainability as a guiding principle in any project will lead to lower production costs. It can also help companies to identify opportunities that will cut costs further in the long term and shrink their environmental footprint at the same time (McKinsey, 2013).

\section{Figure 1: Global energy consumption}

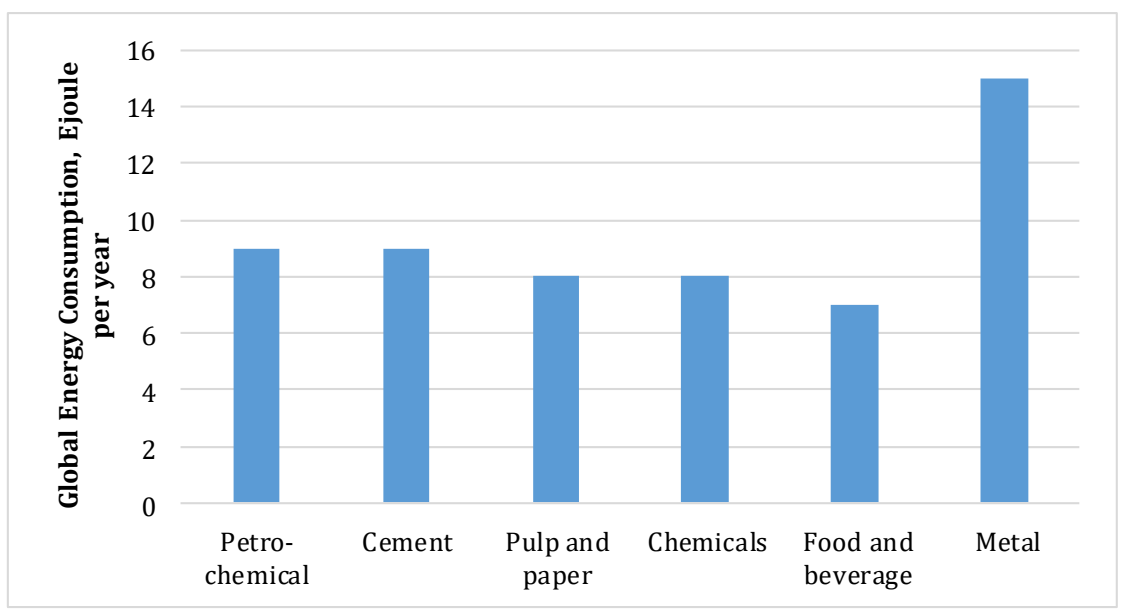

Source: IEA, water business roundtable, world resources institute, US geological survey, Shilomanov, UNDP, Pacific institute, McKinsey analysis

Figure 2: Global water consumption

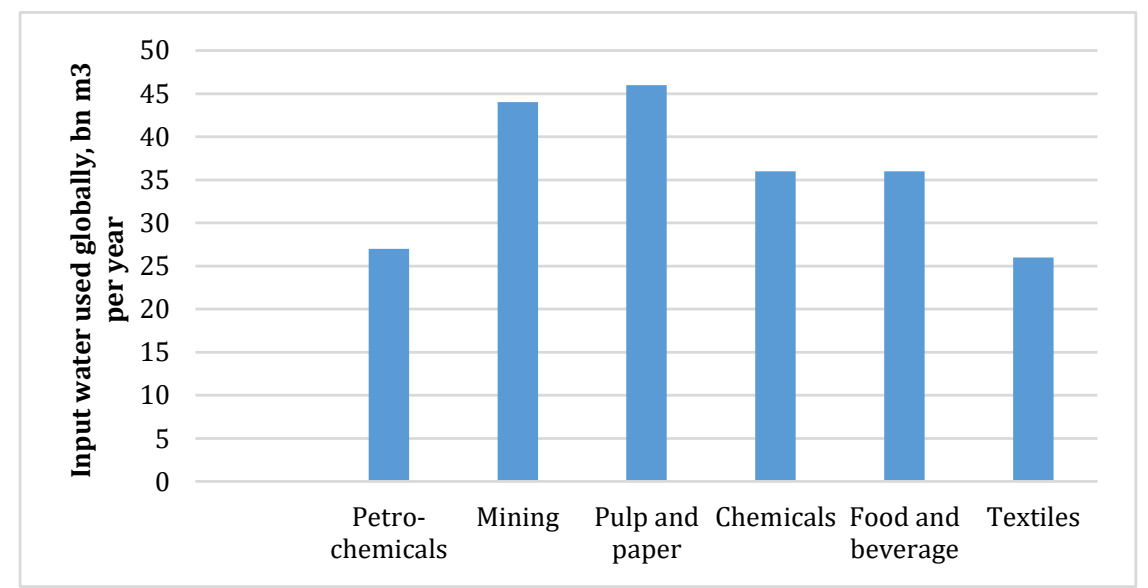

Source: IEA, water business roundtable, world resources institute, US geological survey, Shilomanov, UNDP, Pacific institute, McKinsey analysis

Fluting paper is the middle liner of corrugated board, which can be used individually as a type of protective packaging paper. Fluting provides protection by filling empty spaces in the outer case, providing a cushioning support for the primary product. Being an environmental friendly alternative to traditional packaging materials such as bubble wrap and other plastic based solutions, it is $100 \%$ recyclable and made from a renewable resource. Features of Fluting Paper are as follows: Different weighted paper available for different strength requirements, Shipping available in roll form, Made from 100\% recycled paper, Reduction in transit damage as product remains static inside pack, Boosts level of protection provided by outer case, Cost effective alternative to bespoke designed fitments, Helps optimize your storage space, Easy to handle and use due to its light weight nature environmentally friendly - $100 \%$ recyclable and made from a renewable resources solutions, it is $100 \%$ recyclable and made from a renewable resource. 
The production of pulp for fluting has been the most common use of semi-chemical hardwood pulps. The dominant process for this product is the neutral sulfite semi-chemical process (NSSC), with sodium or ammonium sulfite as cooking chemicals. The pulp yield is in the range of $70-80 \%$ depending on the wood species. Birch, beech, maple, oak and eucalyptus are the most frequently used hardwoods for fluting production, often as the sole component in furnish. Primarily, the demand on a fluting pulp is high stiffness and good crush resistance. A combination of short, stiff fibers and a high proportion of hemicellulose in hardwoods makes them more favorable than softwoods for this purpose (Sixta, 2006).

The main products of packaging paper machines are the base for corrugated board, which shows a steady growth and has a high capacity on the market. Corrugated board consists of at least two outer layers (test liner (TL) or kraft liner), which are glued to a corrugated inner layer (corrugating medium (CM) or fluting) to obtain high bending stiffness (Holik, 2013). TL and CM are made from recycled fibers, whereas kraft liner and fluting from virgin fibers. Fluting or corrugating medium (60-200 gm-2) used for the production of corrugated board has no specified stock composition; however, definite strength properties are required.

The corrugated medium is often 0.026 pounds per square foot $(0.13 \mathrm{~kg} / \mathrm{m} 2)$ basis weight in the USA; in the UK, a 90 grams per square metre $(0.018 \mathrm{lb} / \mathrm{sq} \mathrm{ft})$ fluting paper is common. At the single-facer, it is heated, moistened, and formed into a fluted pattern on geared wheels. This is joined to a flat linerboard with a starch based adhesive to form single face board. At the doublebacker, a second flat linerboard is adhered to the other side of the fluted medium to form single wall corrugated board (Biancolini et al, 2010).

Barimany et al. (2013) investigated the possibility of producing fluting pulp (with a capacity of 20,000 tons a year) from agricultural residues in Iran's Golestan province. The results generally indicated that producing annually 20,000 tons of fluting pulp from agricultural residues in Golestan province was feasible in terms of both provision of raw material and suitability of engineering economy indices. Samariha et al. (2010) investigated, technically and economically, the possibility of producing fluting pulp (with a capacity of 1350 tons) from bagasse in Iran's Khuzestan province. The results indicated that, regarding the agro-industry projects already underway relating to the cane industry and its peripheral industries in the south of Iran, bagasse can be considered as the most suitable non-wood raw material for new fluting paper and pulp mills, and the project is feasible technically and economically. Mines and Industries Ministry (2007) announced that the internal production is not enough to fulfil Iran's demand regarding fluting paper, therefore to export the paper, manufacturers have to consider competition prices and quality of the product in world markets.

Sustainability is development that satisfies the needs of the present without compromising the capacity of future generations, guaranteeing the balance between economic growth, care for the environment and social well-being. Sustainable development is a concept that appeared for the first time in 1987 with the publication of the Brundtland Report, warning of the negative environmental consequences of economic growth and globalization, which tried to find possible solutions to the problems caused by industrialization and population growth (https://www.acciona.com/sustainable-development).

Today, sustainable development in developing countries such as Iran has become a logical necessity. In fact, sustainable development encompasses management of all renewable resources, which is based on supporting the ecosystem and, at the same time, continuously providing human needs.

Sustainable development, while resolving the needs of the present and future generations, also provides a balance with the environment and ecosystem. In recent years, with the aim of preserving forests, it was decided to reduce the utilization of wood from the industrial forests of the north of the country, as a result, active industrial units in the field of pulp and paper and wood products have been faced with a shortage of woody materials. Due to the unproductive use of natural resources in the industry, including the paper industry, as well as the rapid population growth, the environment is on the brink of serious crises, hence discussions on sustainable development have had a great deal of reflection. Considering the economic, social and environmental importance of the paper industry, it is a necessary to move towards sustainable development in the fluting paper industry.

\section{Materials and Methods}

The first stage of this research was carried out as a field study. In addition to reviewing the available literature, large number of experts and specialists, mass producers and members of furniture unions were orally interviewed for determining the indices affecting sustainable development of Iran's fluting paper industry. 
Figure 3: A hierarchy model of criteria and sub criteria

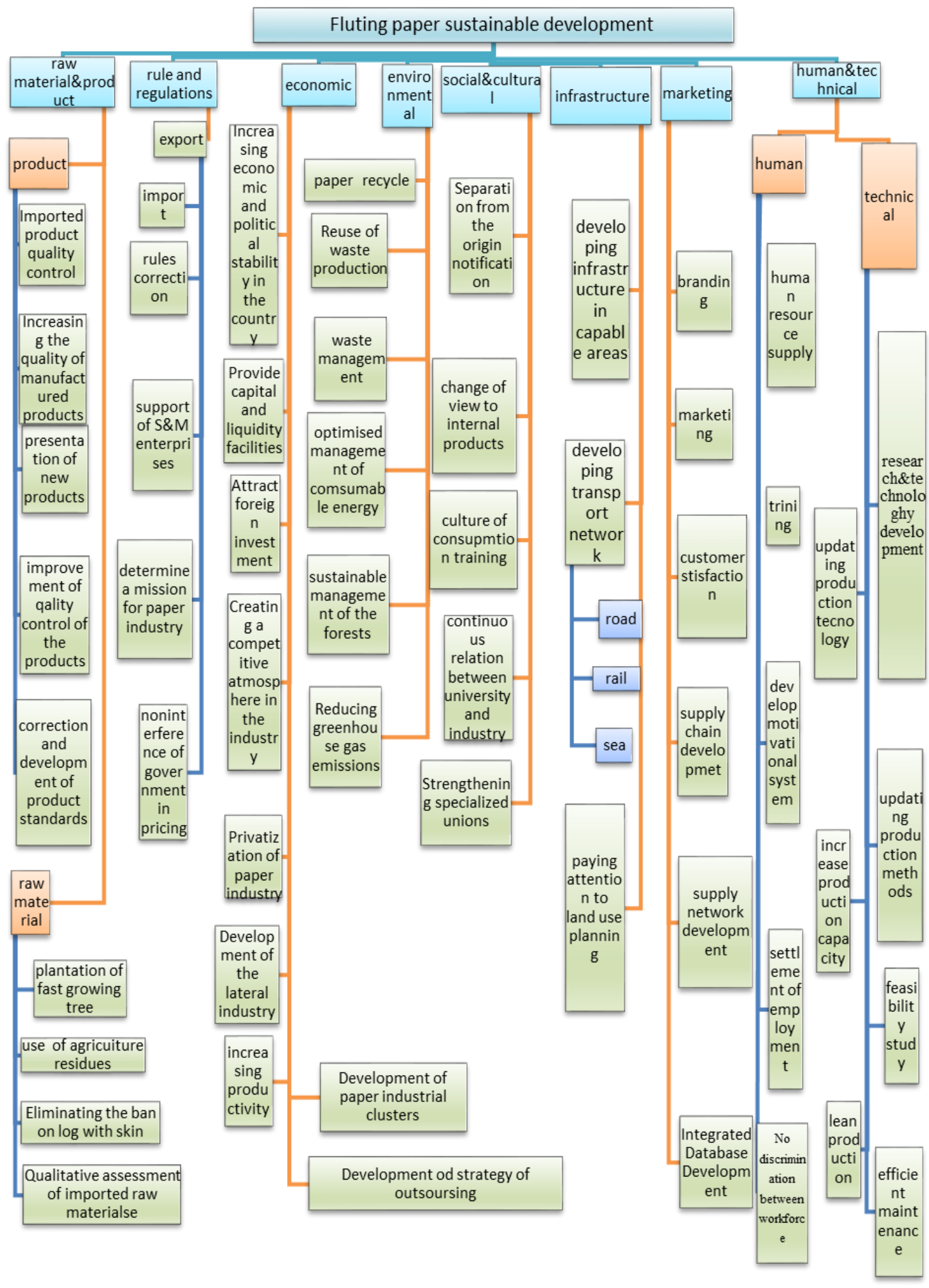

Then, according to the collected data, 55 influencing sub-criteria were identified and categorized in eight general groups including technical and human, cultural-social, economic, materials and products, rules and regulations, infrastructure, marketing and environmental ones; the hierarchy of indices was plotted as shown in Figure 3. Subsequently, in order to prioritize and determine significance degree (weighting value) of each index using AHP (Analytical Hierarchy Process), a questionnaire was designed for paired comparison of these criteria and sub-criteria when distributed among 20 individuals of professional experts and specialists in this industry; the opinions collected through questionnaire were processed by Expert Choice 2000 software. Expert Choice is in this respect intuitive, graphically based and structured in a user-friendly fashion in 
order to be valuable for conceptual and analytical thinkers, novices and experts. Because the objectives are presented in a hierarchical structure, decision-makers are able to "drill down" to their level of expertise, and apply judgments to the objectives deemed important to achieving their goals. At the end of the process, decision-makers are fully confident with how and why the decision was made, with results that are meaningful, easy to communicate, and actionable (Barfod, 2014).

\section{Analysis of Hierarchical Process (AHP)}

AHP method is a collaborative decision-making technique initially devised by Thomas LSaaty in 1970 (Memariani \& Azar, 1995) this method is used in decision-makings that have qualitative and quantitative indices. General structure of this process consists of three main parts: target, criteria \& sub-criteria and choices (options). The numbers used for paired comparison are in the interval between $1 / 9$ and 1 and constitute a standard scale (Saaty, 2001). The mechanism of using this method in the current research comes as follows: after designing hierarchy for the indices influencing sustainable development of floating paper industry, the questionnaire is prepared for paired comparison of the criteria and sub-criteria; opinions of some of related experts are asked regarding significance level of these indices and sub-indices compared to one another. Weighting values of each criteria and sub-criteria are obtained according to the following matrix (Ghodsipour, 2000).

$$
\left[\begin{array}{cccc}
w_{1} / w_{1} & w_{1} / w_{2} & \cdots & w_{1} / w_{n} \\
w_{2} / w_{1} & w_{2} / w_{2} & \cdots & w_{2} / w_{n} \\
\vdots & \vdots & \cdots & \vdots \\
w_{n} / w_{1} & w_{n} / w_{1} & \cdots & w_{n} / w_{n}
\end{array}\right] \Rightarrow\left[\begin{array}{c}
w_{1}\left(\sum_{i=1}^{n} 1 / w_{i}\right) \\
w_{2}\left(\sum_{i=1}^{n} 1 / w_{i}\right) \\
\vdots \\
w_{3}\left(\sum_{i=1}^{n} 1 / w_{i}\right)
\end{array}\right]
$$

If " $n$ " is the number of decision-makers and $a_{i j}$ represents element of $i$-th row and $j$-th column of one of the comparison matrices, the following formula will yield the collaborative judgment concerning $a_{i j}$ :

$$
a_{i j}=\left(a_{i j 1} * a_{i j 2} * a_{i j n}\right)^{*} / 1 / \mathrm{n}
$$

The results will be normalized after computing geometric mean of all paired comparison matrix cells, and, weighting values of criteria and sub-criteria are evaluated through merging weights of low-ranking elements with weight rate of high-ranking elements of the hierarchy. The important point about paired comparison matrices is their inconsistency ratio; according to Professor Saaty, for having consistent judgments, inconsistency ratio of matrices need to be equal or less than 0.1 (Saaty, 1980).

\section{Results}

\section{Table 1: Weighting values of main criteria (Inconsistency ratio $=\mathbf{0 . 0 8}$ )}

\begin{tabular}{lc}
\hline Criteria & Weighting value \\
\hline Economic & 0.282 \\
Material and product & 0.235 \\
Social and cultural & 0.169 \\
Technical and human & 0.107 \\
Environmental & 0.104 \\
Marketing, Sale and supplies & 0.046 \\
Rules and regulations & 0.031 \\
Infrastructure & 0.027 \\
\hline
\end{tabular}


Figure 4: Overall result of weighting value of sub criteria (Inconsistency ratio $=0.08$ )
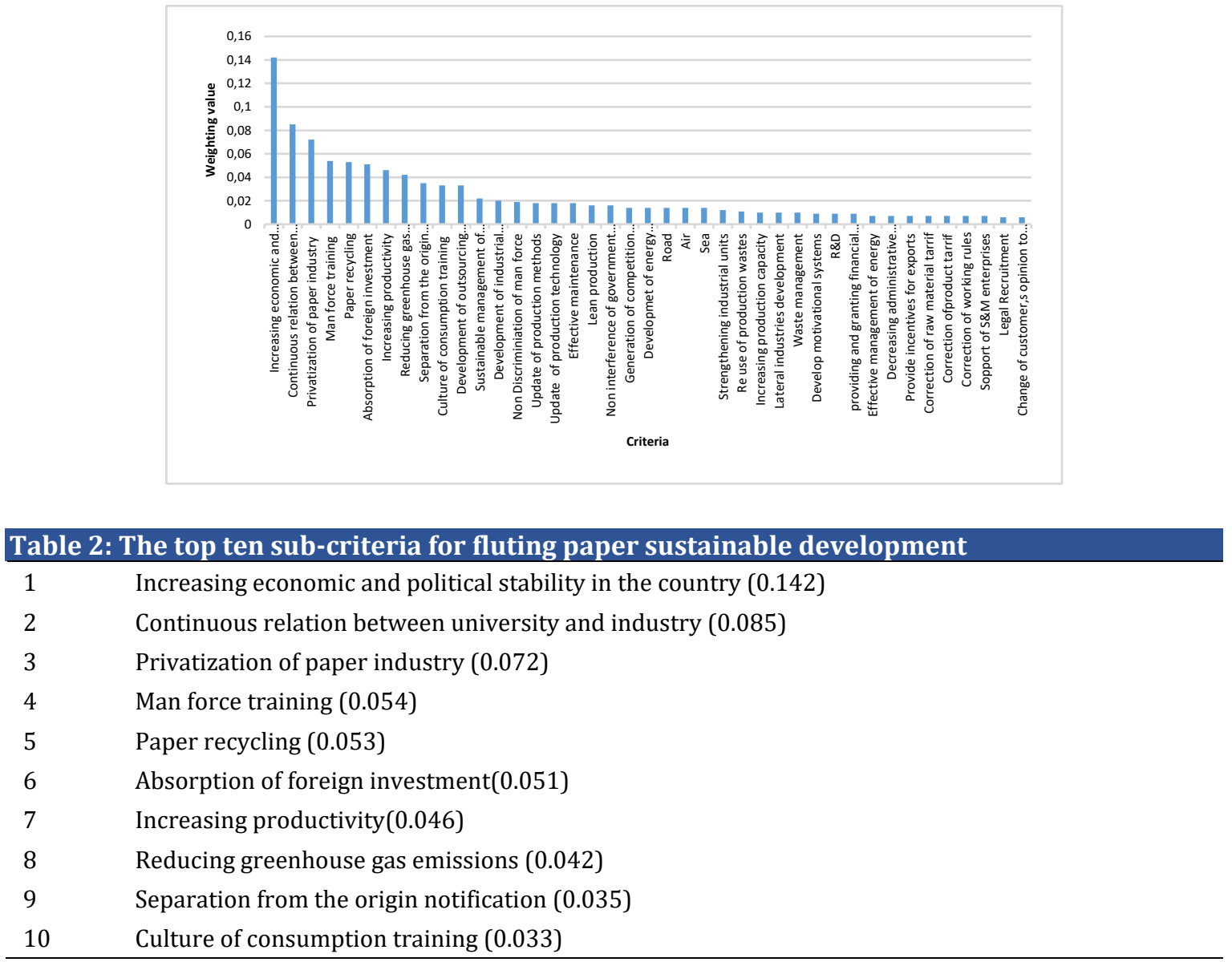

(Inconsistency ratio: 0.08 )

\section{Discussion}

According to the results (figure 2 and table 2), total inconsistency ratio of matrices equals 0.08 which is indicative of the fact that results are consistent and compatible. Results also show that the sub-indices of Increasing economic and political stability in the country, Continuous relation between university and industry, Privatization of paper industry, Man force training, Paper recycle, Absorption of foreign investment, and Increasing productivity assume the highest weighting values for achieving sustainable development of Iran's floating paper industry. Reasons for high significance of these indices can be explained and discussed as follows:

Increasing economic and political stability in the country (weighting value: 0.142):

Developing successfully of investment in industrial sector depends on existence of financial security for the investor. Also, according to investigation of World Bank, economic instability has been known as one of the important factors impacting non-development of different industries (Meydari, 2006). Based on the views of paper producers and experts, the investors presently prefer to invest on other countries or on brokering activities which require lower risk due to reasons such as inconsistency of raw materials price and customs tolls, unclear and unstable condition of imports and exports, and as a result, absence of financial security and return on equity. In a developing country like Iran where development plans are greatly influenced by sudden changes in governments' approaches toward large and small-scale political and economic strategies, establishment of permanent or long-term economic stability is not possible, at least in mid-term. Consequently, it is potentially risky to make investment on industries such as paper making. Under such circumstances, governments can provide the possibility for attraction of foreign and domestic investors to invest on this industry through executing solutions like production support via granting loans or effective long-term insurances to the investors, observing taxation equality or allocating tax exemptions, precise control over paper exports and imports, and lastly, controlling price of raw materials from one hand and establishing consistent political and economic relations with regional countries from the other hand. 


\section{Continuous relation between university and industry (weighting value: 0.085 ):}

University in the modern world is one of the most influential centers in new comments.

Academic research orientations to the needs of the industrial sector can have important effects on the performance and sustainable development of industries. Historical process of economic and industrial development of developed countries has shown that the dynamic of the educational system and the deep link between science and technology are one of the important factors of economy and culture. Investment in research programs is a long term investment for the future. Managers of Research \& Development branches of the factories and research organizations must have an active link and collaborate with other $\mathrm{R} \& \mathrm{D}$ units.

Privatization of paper industry (weighting value: $\mathbf{0 . 0 7 2}$ ):

For Implementation of economic structure improvement program and enhancement of economic development, access to foreign financial resources is as significant as access to domestic capital. In order to attract this requisite foreign investment, policy aimed at reducing investment risk should be implemented. Privatization is the most effective policy that the governments implement in order to attract foreign investment. Stability of rules, tariff system, insurance, employer-employee relations, investment security, and special supports of banking system and social security laws are the most important principles in this regard (Azizi and Ray 2016). Jafari (2009) explained that the main problem in paper industry is the private section. According to FAO reports, the amount of paper consumption is more than one million tones, but since investing on this section is often heavy, private section is not able to found large unit of paper making like Chuka and Mazandaran Wood and Paper. Therefore, investing is the main challenge in paper industry and it is needed to help this section to be more active for removing infections and increasing production.

\section{Man force training (weighting value: 0.054):}

The investment in training that a company makes shows employees that they are valued. The training creates a supportive workplace. Employees may gain access to training they wouldn't have otherwise known about or sought out themselves. Employees who feel appreciated and challenged through training opportunities may feel more satisfaction toward their jobs. Most employees will have some weaknesses in their workplace skills. A training program allows you to strengthen those skills that each employee needs to improve. A development program brings all employees to a higher level so they all have similar skills and knowledge. This helps reduce any weak links within the company who rely heavily on others to complete basic work tasks. Providing the necessary training creates an overall knowledgeable staff with employees who can take over for one another as needed, work on teams or work independently without constant help and supervision from others.

Paper recycling (weighting value: 0.053 ):

Paper produced from virgin raw material uses more energy and water in comparison with recycled paper. Paper recycling is one of the ways to prevent forest loss. Recycling has three important uses for the environment, including saving on natural resources by the use of recycled materials instead of virgin raw materials for the production of new products. Energy saving is another benefit of recycling. The third best recycling option requires less space for burial Rubbish Recycling paper. In addition to being profitable, contaminates water by up to $35 \%$, air pollution up to $74 \%$ and Energy consumption are reduced by 24 to 54 percent.

Absorption of foreign investment (weighting value: 0.051 ):

Absorption of foreign investment in fluting paper industry is vital because of high costs of machines and modern technology. Problem of the investment can be solved via acquisition of foreign investment which will lead to technology transfer of building, planning, research and development. Encouragement of foreign investment makes the most considerable impact on decrease of budget deficiency and national debts as well (Azizi \& Ray, 2016). Encouragement of foreign investment would create a situation leading to the increase attraction of domestic and foreign investment in fluting paper industry. Encouragement for investment provides plenty of opportunities for privatization and economic activities. 


\section{Conclusion}

It can be stated that according to result obtained by AHP in this research, indices of Increasing economic and political stability in the country, Continuous relation between university and industry, Privatization of paper industry, Man force training, Paper recycle and Absorption of foreign investment have the highest priority respectively. The results of this research can be presented as a road map for the correct path of sustainable development, which will provide suitable solutions to improve the performance of the manufacturers of the fluting paper industry. The creation of structural reforms in various sectors of the industry aimed at achieving international markets and sustainable development is another achievement of this research.

\section{Appendix A. Supplementary material}

Supplementary data associated with this article can be found, in the online version, at https://doi.org/10.14254/jems.2018.3-2.2

\section{Funding}

The authors received no direct funding for this research.

\section{Citation information}

Azizi, M., Mohebbi, N., \& Azadfallah, M. (2018). Determining effective criteria on sustainable development of fluting paper making industry. Economics, Management and Sustainability, 3(2), 2028. doi:10.14254/jems.2018.3-2.2.

\section{References}

Azizi, M., \& Ray, C. (2016). Proposing a decision model for privatization of newsprint paper industry by applying ANP. Cogent Business \& Management, 3, 1197088.

Barfod, M. B. (2014). Graphical and technical options in Expert Choice for group decision making. First edition, DTU Lyngby: Technical University of Denmark, Transport.

Aboksari, A. B., Azizi, M., Gasemian, A., \& Mohebbi, N. (2013). Economic assessment of producing a fluting paper using agricultural residues - a case study: Iran, Mazandaran Province. International Journal of Sustainable Engineering, 6(3), 278-284. DOI:10.1080/19397038.2012.727497

Biancolini, M. E., Brutti, C., \& Porziani, S. (2010). Corrugated board containers design methods. International Journal of Computational Materials Science and Surface Engineering, 3(2-3), 143-163.

Ghodsipour, H. (2000). Analytical Hierarchy Process. Amir Kabir Univ. press, 220p (In Persian).

Holik, H. (2013). Handbook of Paper and Board. WileyVCH Verlag GmbH \& Co.

Iran Ministry of Industries and Mines web page. (2007). Retrieved from http://intl.mim.gov.ir.

Jafari, A. (2009). Sanat news' website. Retrieved from http://www.sanatnews.ir.

McKinsey. (2013). Sustainability value creation in the pulp and paper industry through sustainability transformation. Retrieved from https://www.mckinsey.com/industries/paperandforestproducts.

Memariani, A., \& Azar, A. (1995). AHP, A new technic for group decision making. Science of Management, 22(2), 28-32.

Meydari, A. (2006). Assessing laws and regulations in Iran: Necessities and Recommendations. Retrieved from http://nokhbeh.ir/newnokhbeh.

Occiona corporations. (2016). What if the smartest decision was to invest in the planet? Retrieved from https://www.acciona.com/sustainabledevelopment

Saaty, T.L. (2001). Decision Making with Dependence and Feedback: The Analytic Network Process. RWS publications, Pittsburgh, PA, USA. 
Saaty, T.L. (1980). The analytic Hierarchy Process. McGrawHill international, New York, RWS Publications, Pittsburgh, USA.

Samariha, A., Hemasi, A. H., \& Kiaei, M. (2010). Economically Study on Possibility of Making Floating Paper from bagasse in Khouzestan province. Journal of Sciences and Techniques in Natural Resources, 5(2), 49-60.

Sixta, H. (2006). Handbook of Pulp. WILEY-VCH Verlag GmbH \& Co. KgaA.

C) 2016-2018, Economics, Management and Sustainability. All rights reserved. This open access article is distributed under a Creative Commons Attribution (CC-BY) 4.0 license. You are free to:

Share - copy and redistribute the material in any medium or format Adapt - remix, transform, and build upon the material for any purpose, even commercially.

The licensor cannot revoke these freedoms as long as you follow the license terms.

Under the following terms:

Attribution - You must give appropriate credit, provide a link to the license, and indicate if changes were made.

You may do so in any reasonable manner, but not in any way that suggests the licensor endorses you or your use.

No additional restrictions

You may not apply legal terms or technological measures that legally restrict others from doing anything the license permits.

Economics, Management and Sustainability (ISSN: 2520-6303) is published by Scientific Publishing House "CSR", Poland, EU and Scientific Publishing House "SciView", Poland

Publishing with JEMS ensures:

- Immediate universal access to your article on publication

- High visibility and discoverability via the JEMS website

- Rapid publication

- Guaranteed legacy preservation of your article

- Discounts and waivers for authors in developing regions

Submit your manuscript to a JEMS at http://iems.sciview.net or submit.jems@sciview.net

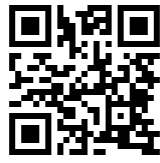

